\title{
Effect of Annealing on the Structure and Photoluminescence of Eu-Doped ZnO Nanorod Ordered Array Thin Films
}

\author{
Wen-Wu Zhong, ${ }^{1}$ Da-Wei Guan, ${ }^{2}$ Yue-Lin Liu, ${ }^{3}$ Li Zhang, ${ }^{1}$ Yan-Ping Liu, ${ }^{1}$ \\ Zhi-Gang Li, ${ }^{1}$ and Wei-Ping Chen ${ }^{1}$ \\ ${ }^{1}$ Department of Physics, Taizhou University, Taizhou 318000, China \\ ${ }^{2}$ Department of Vessel Engineering, Wuhan Institute of Shipbuilding Technology, Wuhan 430050, China \\ ${ }^{3}$ Department of Physics, Yantai University, Yantai 264005, China
}

Correspondence should be addressed to Zhi-Gang Li, lizhigang@issp.ac.cn and Wei-Ping Chen, cwp@tzc.edu.cn

Received 18 October 2012; Accepted 7 December 2012

Academic Editor: Yue Li

Copyright (C) 2012 Wen-Wu Zhong et al. This is an open access article distributed under the Creative Commons Attribution License, which permits unrestricted use, distribution, and reproduction in any medium, provided the original work is properly cited.

\begin{abstract}
Eu-doped $\mathrm{ZnO}$ nanorod ordered array thin films were synthesized on glass substrates with a $\mathrm{ZnO}$ seed layer via hydrothermal method. XRD reveals that the (002) diffraction peak of films annealed in hydrogen is sharper than that annealed in air. SEM reveals that the nanorods of films annealed in hydrogen are shortened and widened. TEM results demonstrate that the nanorods are single crystalline and the lattice spacing of $0.52 \mathrm{~nm}$ agrees with the $d$ spacing of $(001)$ crystal planes along $c$-axis. Room temperature photoluminescence (PL) reveals that the PL of films annealed in hydrogen is the strongest and shifts to lower wavenumber. The point defect of Eu-doped $\mathrm{ZnO}$ nanorod array thin film is transferred from $\mathrm{O}_{\mathrm{i}}$ to $\mathrm{O}_{\mathrm{Zn}}$ by annealing in hydrogen.
\end{abstract}

\section{Introduction}

Zinc oxide is an important member in the II-VI family with a wide band gap $(3.37 \mathrm{eV})$ and a large excitonic binding energy $(60 \mathrm{meV})$ [1-5]. Furthermore, $\mathrm{ZnO}$ is one of the environmental friendly materials, and the impurity-doped $\mathrm{ZnO}$ nanocrystals emitting visible light are expected to be appropriate materials for flat panel displays, florescence labels for biological imaging, and so on [6]. High quality II-VI semiconductor nanocrystals also become materials for doping of optically active impurities. The II-VI semiconductor nanocrystals doped with luminescence centers exhibit efficient luminescence even at room temperature [7-9].

Rare-earth ions are unique dopants, because they are optically and magnetically active in the semiconductor host crystals [10]. It is anticipated that in impurity-doped $\mathrm{ZnO}$, strong interactions between the quantum-confined carriers and localized electrons on impurities will produce efficient photoluminescence (PL) $[11,12]$. Eu is an attractive dopant for red emission in the range of $540-665 \mathrm{~nm}$ and the $\mathrm{Eu}-$ related luminescence lines are found to be a strong function of the structural quality and thermal cycling in the case of $\mathrm{GaN}$ [13].

In addition, nanorod thin films have some interesting properties. Among various synthesis methods, the hydrothermal method is attractive through which $\mathrm{ZnO}$ nanorods can be fabricated at low cost [14]. Despite various $\mathrm{ZnO}$ nanostructures that have been produced, few work has been executed on the synthesis of rod-like Eu-doped $\mathrm{ZnO}$ array thin films. In our work, via a low-temperature $\left(70^{\circ} \mathrm{C}\right)$ hydrothermal synthesis, we present a nontoxic, large-scale, and low-cost method of preparing morphology-controlled Eudoped nanorod $\mathrm{ZnO}$ array thin films on glass substrates with $\mathrm{ZnO}$ seed layer, and the effects of annealing atmosphere and Eu-doping on crystalline orientation and luminescence of the $\mathrm{ZnO}: \mathrm{Eu}$ films are also investigated.

\section{Experimental Details}

2.1. Preparation of $\mathrm{ZnO}$ Seed Layer. The $\mathrm{ZnO}$ seed layer was prepared on glass substrates by the sol-gel spin-coating method. Zinc acetate $\left[\mathrm{Zn}\left(\mathrm{CH}_{3} \mathrm{COO}\right)_{2} \cdot 2 \mathrm{H}_{2} \mathrm{O}\right]$ was used as 


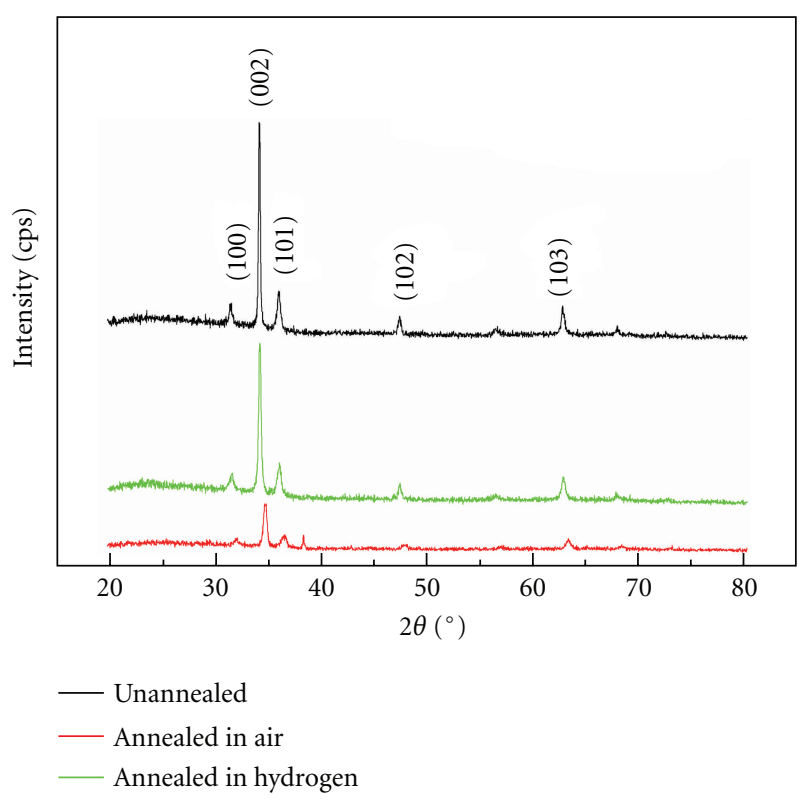

Figure 1: X-ray diffraction patterns of the Eu-doped nanorod $\mathrm{ZnO}$ array thin films.

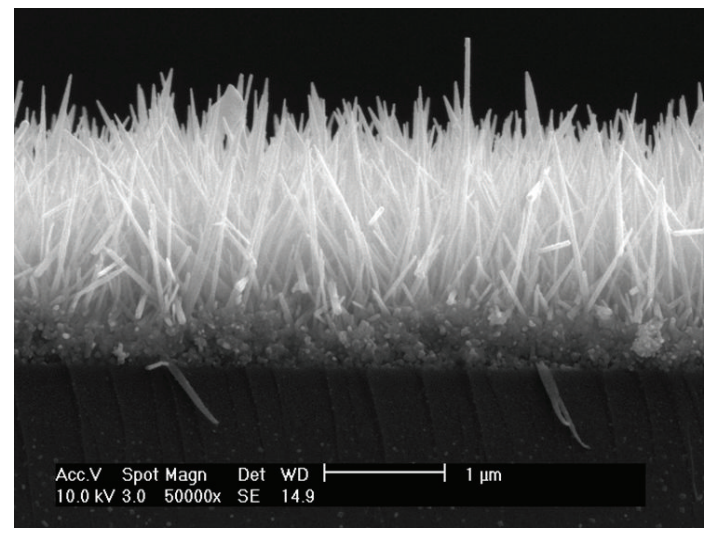

(a)

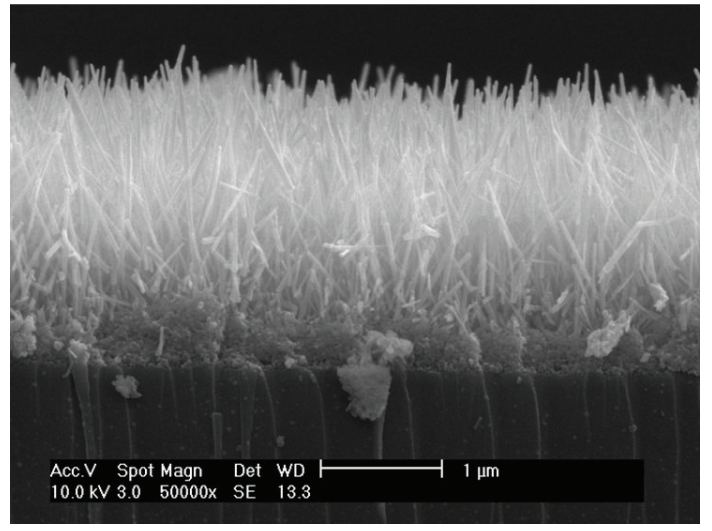

(b)

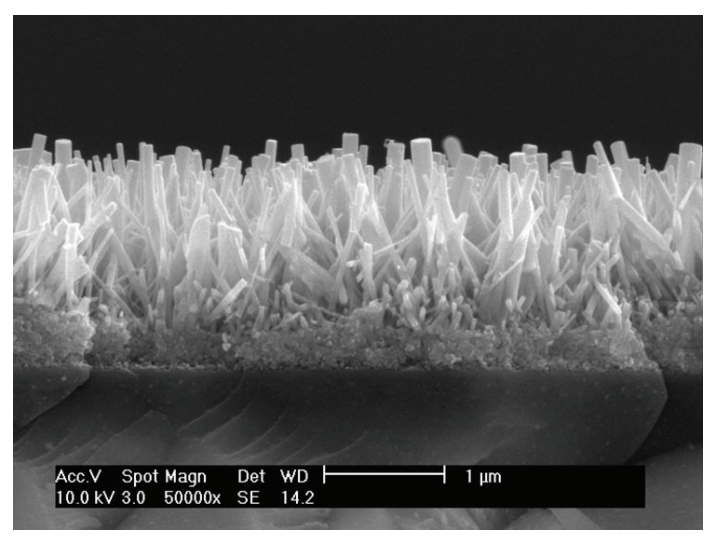

(c)

FIGURE 2: Secondary electronic microscopy micrographs of Eu-doped ZnO nanorod array thin films: (a) unannealed, (b) annealed in air, (c) annealed in hydrogen. 


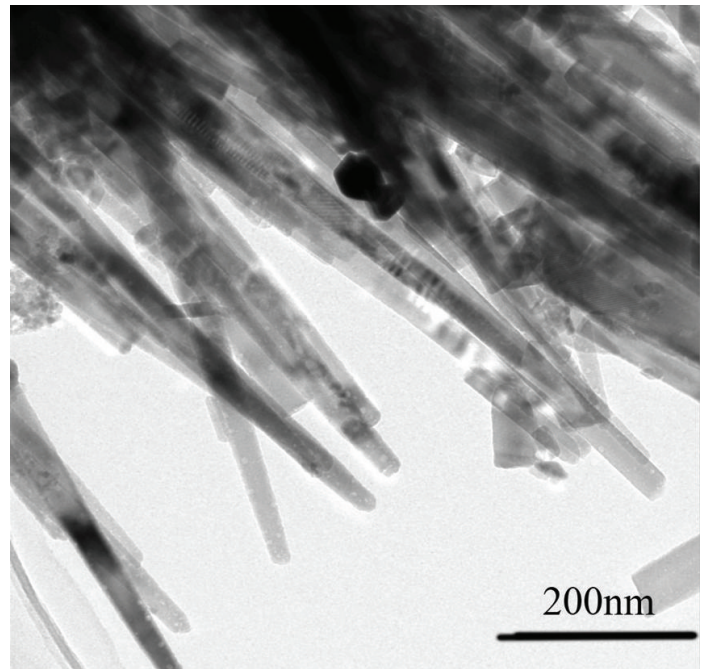

(a)

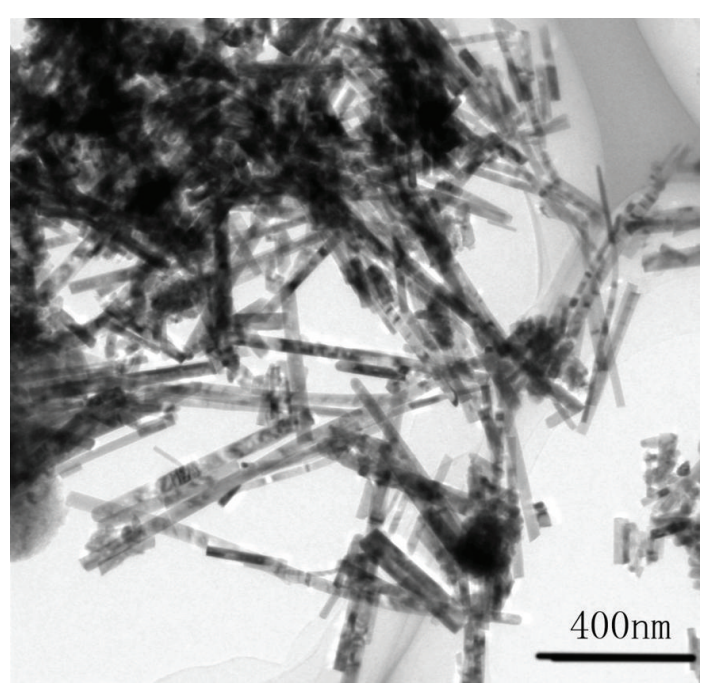

(b)

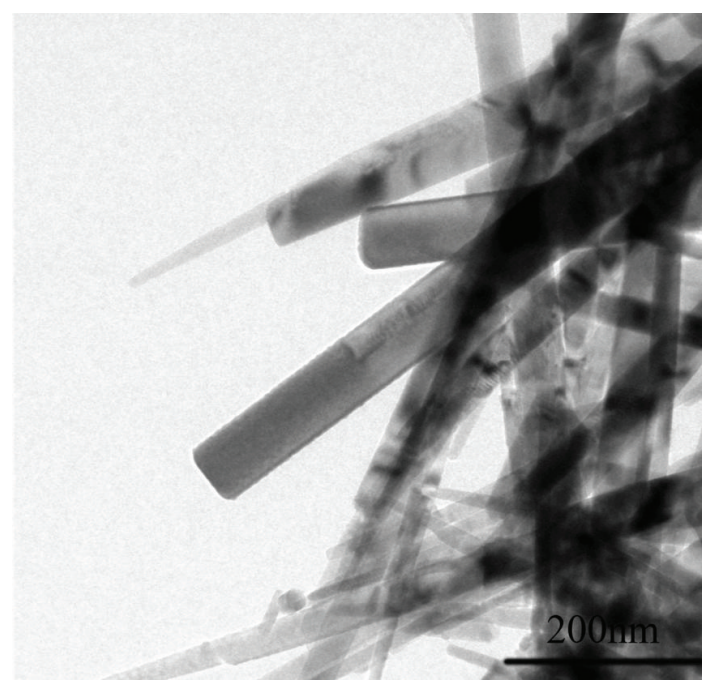

(c)

FIGURE 3: Low-resolution cross-sectional TEM image of the ZnO nanorods: (a) unannealed, (b) annealed in air, (c) annealed in hydrogen.

a basic chemical. Ethylene glycol monomethyl ether $\left(\mathrm{C}_{3} \mathrm{H}_{8} \mathrm{O}_{2}\right)$ and ethanolamine $\left(\mathrm{C}_{2} \mathrm{H}_{7} \mathrm{NO}\right)$ were used as solvent and stabilizer, respectively. The molar ratio of ethanolamine to zinc acetate was $1: 1$ and the concentration of the solution was $0.8 \mathrm{~mol} / \mathrm{L}$. The obtained mixture was stirred at $60^{\circ} \mathrm{C}$ for $4 \mathrm{~h}$ to yield a clear and homogeneous solution, which then served as the coating source after being cooled down to room temperature. The glass substrates were first cleaned in detergent, then in methanol and acetone using an ultrasonic cleaner, for $30 \mathrm{~min}$ each. Finally, the glass substrates were rinsed with deionized water and dried in oven. The coating solution was then dropped onto the glass substrate, which was rotated at $3000 \mathrm{rpm}$ for $30 \mathrm{sec}$ using $\mathrm{KW}-4 \mathrm{~A}$ spin coater. After spin coating, the films were dried at $350^{\circ} \mathrm{C}$ for $20 \mathrm{~min}$ in a furnace to evaporate the solvent and remove organic residuals. This coating/drying procedure was repeated for three times before the films were inserted into a tube furnace and annealed at $550^{\circ} \mathrm{C}$ for $2 \mathrm{~h}$ in air.
2.2. Film Growth by Hydrothermal Method. At room temperature, diluted ammonia solution was dripped into the zinc nitrate solution under stirring, and requisite $\mathrm{Eu}_{2} \mathrm{O}_{3}$ was dissolved into dilute $\mathrm{HNO}_{3}$. By mixing the above two solutions, we obtain one with Au-Zn molar ratio of $1: 50$, in which zinc nitrate was $0.54 \mathrm{~g}$ and the volume of solution was $40 \mathrm{~mL}$. The glass substrates with the seed layer were immersed into the teflon lined stainless steel autoclaves filled with the resultant solution, and then the sealed vessels were put in the oven for heating at $70^{\circ} \mathrm{C}$ for $5 \mathrm{~h}$. The grown films were rinsed with deionized water and dried in the air.

2.3. Characterization. The crystal graphic interpretations were performed on an X'Pert Pro XRD system with X-ray Mirror PFX at an operation voltage of $40 \mathrm{kV}$ and a current of $40 \mathrm{~mA}$, in which $\mathrm{Cu} \mathrm{K \alpha}(\lambda=0.154059 \mathrm{~nm})$ was used and scanned in a $2 \theta$ range from $15^{\circ}$ to $80^{\circ}$. Surface morphology and thickness of the film were studied via an FEI-SIRION 


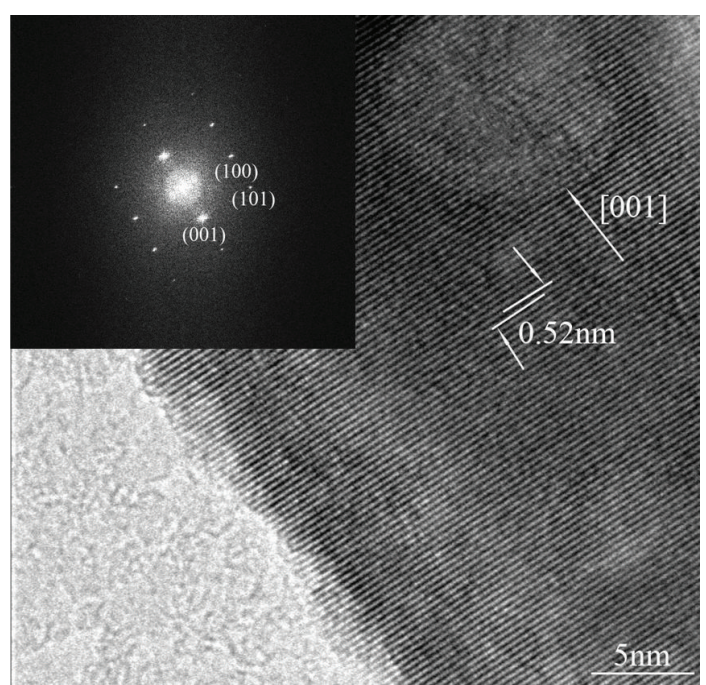

(a)

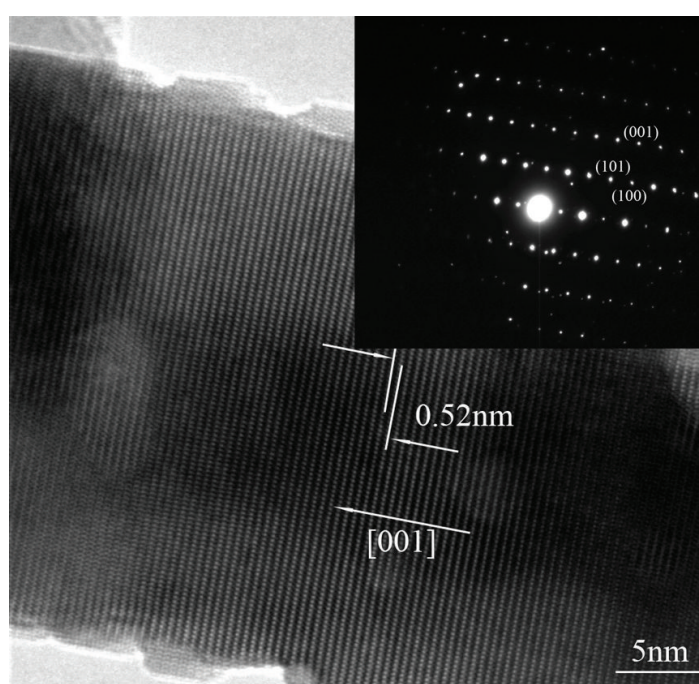

(b)

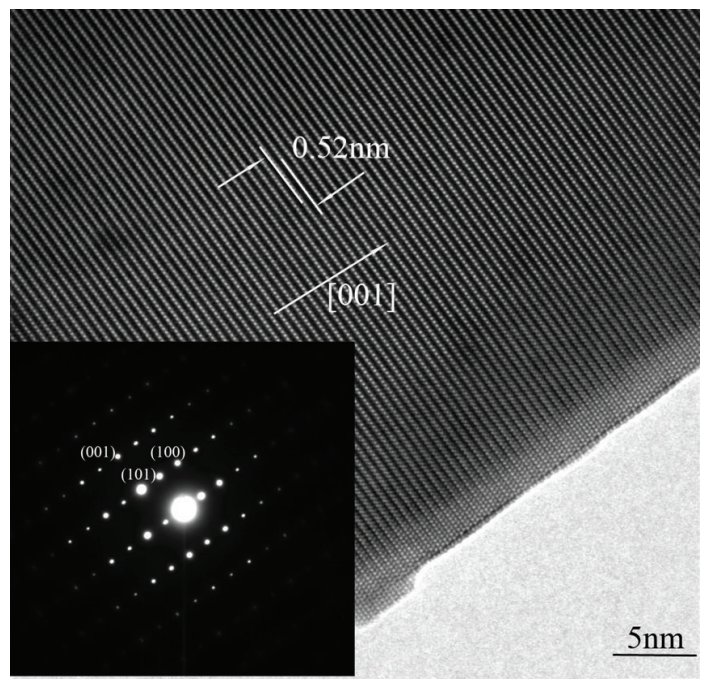

(c)

FIGURE 4: High-resolution TEM image of the $\mathrm{ZnO}$ array thin films together with the corresponding SAED pattern (inset): (a) unannealed, (b) annealed in air, (c) annealed in hydrogen.

scanning electron microscope (SEM). Transmission electron microscope (TEM) micrographs and selected-area electron diffraction (SAED) patterns were obtained on a PHILIPSCM200 and JEM-2010 type TEM. The PL spectra were recorded from 330 to $800 \mathrm{~nm}$ at room temperature by a $325 \mathrm{~nm}$ excitation from Xe lamp (F-4500 Fluorescence Spectrophotometer).

\section{Results and Discussion}

3.1. Structure and Surface Morphology. Figure 1 shows the XRD patterns of the samples deposited on glass substrate with $\mathrm{ZnO}$ seed layer by hydrothermal synthesis under different annealing atmosphere. All the diffraction peaks can be indexed to a hexagonal wurtzite $\mathrm{ZnO}$ structure $(a=$ $0.325 \mathrm{~nm}, c=0.521 \mathrm{~nm}$ ) and no peaks are detected from any impurities. The (002) reflection sharps up distinctly, indicating the $c$-axis of $\mathrm{ZnO}$ nanocrystals is oriented perpendicular to the plane of the $\mathrm{ZnO}$ seed layer. It can be also seen that the (002) diffraction peak is the strongest when the film is not annealed, and that which annealed in hydrogen is the second, while that annealed in air is the last. These results indicate that the prepared $\mathrm{ZnO}$ using the present method is highly crystallized.

Furthermore, in our experimental condition, a novel one-dimensional nanorod array thin film of $\mathrm{ZnO}$ was synthesized. The SEM micrographs of Eu doped $\mathrm{ZnO}$ nanorod array thin films are shown in Figure 2, in which Figures 2(a), 2(b), and 2(c) represent unannealed, annealed in air, and annealed in hydrogen of samples, respectively. From these pictures, it can be seen that nanorods are grown vertically oriented with seed layer. Notably, when the films were 


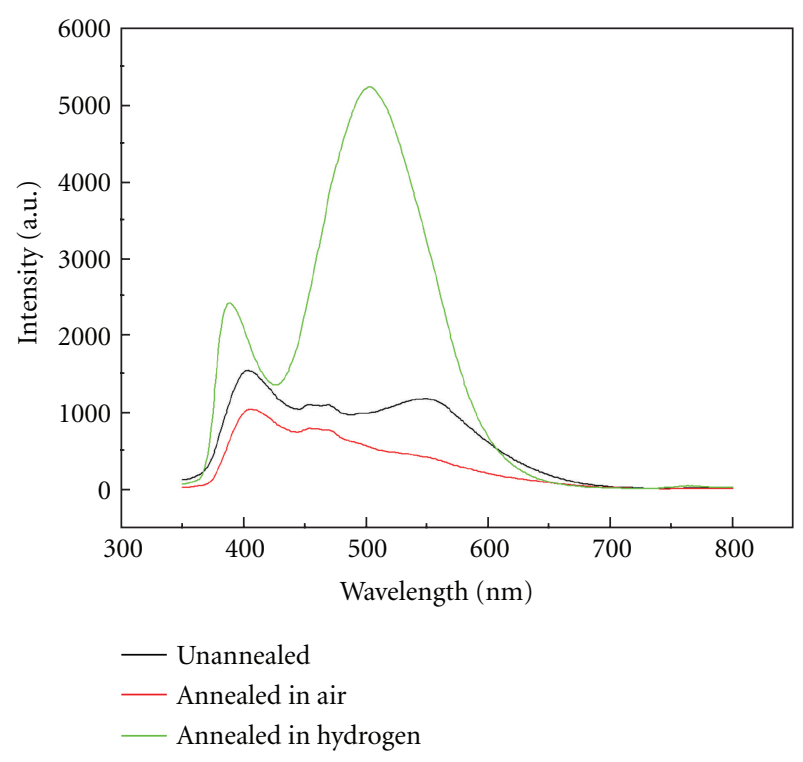

Figure 5: PL spectra of Eu-doped ZnO nanorod array thin films.

annealed in hydrogen, the nanorods become shorter and wider. In addition, the typical EDS pattern of the nanorod indicates that the film consists of $\mathrm{Zn}, \mathrm{O}$, and $\mathrm{Eu}$, and the molar ratio of $\mathrm{Zn}, \mathrm{O}$, and $\mathrm{Eu}$ is $48: 0.4: 51.6$. The results reveal that the Eu atom might be doped into the nanorod in the form of substitution.

To characterize the crystallinity of the $\mathrm{ZnO}$ nanorods by TEM, we remove the products from the seed layer by ultrasonication in the ethanol. Figure 3 displays the TEM images of Eu doped $\mathrm{ZnO}$ nanorod array thin films. Among them, Figures 3(a), 3(b), and 3(c) denote the samples which are unannealed, annealed in air, and annealed in hydrogen, respectively. Those figures show that $\mathrm{ZnO}$ nanorods are straightforward with nonuniform diameter along their axis, and the $\mathrm{ZnO}$ nanorods are the widest when the films were annealed in hydrogen.

In Figure 4, we display the high-resolution TEM images and the corresponding SAED pattern of Eu doped $\mathrm{ZnO}$ nanorod array thin films. In a similar way, Figures 4(a), 4(b), and 4 (c) denote the samples which are unannealed, annealed in air, and annealed in hydrogen, respectively. Those images further confirm that the nanorods are single crystalline and the obtained lattice spacing of $0.52 \mathrm{~nm}$ agrees with the $d$ spacing of (001) crystal planes along $c$-axis, which is also supported by SAED patterns (inset in Figure 4).

3.2. PL Spectra. Figure 5 shows the PL spectra of the Eudoped $\mathrm{ZnO}$ nanorod array thin films. We detected that the unannealed films have emission at 400 , and $560 \mathrm{~nm}$, the films annealed in air have emission at $400 \mathrm{~nm}$, and the films annealed in hydrogen have emission at 390, and $520 \mathrm{~nm}$. Furthermore, the figure confirms that the PL of films annealed in hydrogen is the strongest and shifts to lower wavenumber. Srikant and Clarke assigned the UV emission at $\sim 395 \mathrm{~nm}$ to a shallow donor [15], and the nature of the shallow donor might be the complex defect of $\mathrm{Zn}_{\mathrm{i}}$ [16].
The peak at $\sim 520 \mathrm{~nm}$ remains controversial and is more preferably attributed to $\mathrm{O}_{\mathrm{Zn}}[17,18]$. The origin of yellow and orange luminescence $(>540 \mathrm{~nm})$ is ascribed to $\mathrm{O}_{\mathrm{i}}[19]$. The above analysis verifies our assumption that the films unannealed have point defect $\mathrm{O}_{i}$, and the films annealed in hydrogen have point defect $\mathrm{O}_{\mathrm{Zn}}$. In a word, the point defect of Eu-doped $\mathrm{ZnO}$ nanorod array thin film is transferred from $\mathrm{O}_{\mathrm{i}}$ to $\mathrm{O}_{\mathrm{Zn}}$ by annealing in hydrogen.

\section{Conclusions}

In summary, we present the fabrication of the Eu-doped $\mathrm{ZnO}$ nanorod ordered array thin films via hydrothermal method. Test results demonstrate that the (002) diffraction peak of films annealed in hydrogen is sharper than that annealed in air, and the nanorods of films annealed in hydrogen become shorter and wider. TEM results further demonstrate that the nanorods are single crystalline and the obtained lattice spacing of $0.52 \mathrm{~nm}$ agrees with the $d$ spacing of (001) crystal planes along $c$-axis. Room temperature photoluminescence reveals that the PL of films annealed in hydrogen is the strongest and shifts to lower wavenumber. The point defect of Eu-doped $\mathrm{ZnO}$ nanorod array thin film is transferred from $\mathrm{O}_{\mathrm{i}}$ to $\mathrm{O}_{\mathrm{Zn}}$ by annealing in hydrogen.

\section{Acknowledgments}

The authors gratefully acknowledge the financial support of the project by National Natural Science Foundation of China (Grant nos. 51001078 and 51202155) and Zhejiang Provincial Natural Science Foundation of China (Grant nos. Y4110207 and Y4110547).

\section{References}

[1] B. Cao, Y. Li, G. Duan, and W. Cai, "Growth of ZnO nanoneedle arrays with strong ultraviolet emissions by an electrochemical deposition method," Crystal Growth and Design, vol. 6, no. 5, pp. 1091-1095, 2006.

[2] B. Cao, X. Teng, S. H. Heo et al., "Different $\mathrm{ZnO}$ nanostructures fabricated by a seed-layer assisted electrochemical route and their photoluminescence and field emission properties," Journal of Physical Chemistry C, vol. 111, no. 6, pp. 2470-2476, 2007.

[3] M. Kashif, U. Hashim, M. E. Ali et al., "Effect of different seed solutions on the morphology and electrooptical properties of ZnO nanorods," Journal of Nanomaterials, vol. 2012, Article ID 452407, 6 pages, 2012.

[4] L. Zhang, Y. K. Takahashi, A. Perumal, and K. Hono, "L1 $0^{-}$ ordered high coercivity (FePt)AgC granular thin films for perpendicular recording," Journal of Magnetism and Magnetic Materials, vol. 322, no. 18, pp. 2658-2664, 2010.

[5] Z. G. Li, Y. P. Liu, P. S. Liu, W. P. Chen, S. S. Feng, and W. W. Zhong, "Fabrication and morphology dependent magnetic properties of cobalt nanoarrays via template-assisted electrodeposition," RSC Advances, vol. 2, p. 3447, 2012.

[6] A. Ishizumi, Y. Takahashi, A. Yamamoto, and Y. Kanemitsu, "Fabrication and optical properties of Eu3+-doped $\mathrm{ZnO}$ nanospheres and nanorods," Materials Science and Engineering $B$, vol. 146, no. 1-3, pp. 212-215, 2008. 
[7] A. Ishizumi, Y. Taguchi, A. Yamamoto, and Y. Kanemitsu, "Luminescence properties of $\mathrm{ZnO}$ and $\mathrm{Eu}^{3+}$-doped $\mathrm{ZnO}$ nanorods," Thin Solid Films, vol. 486, no. 1-2, pp. 50-52, 2005.

[8] H. Zeng, G. Duan, Y. Li, S. Yang, X. Xu, and W. Cai, "Blue luminescence of $\mathrm{ZnO}$ nanoparticles based on non-equilibrium processes: defect origins and emission controls," Advanced Functional Materials, vol. 20, no. 4, pp. 561-572, 2010.

[9] H. Zeng, C. Zhi, Z. Zhang et al., "”White graphenes": boron nitride nanoribbons via boron nitride nanotube unwrapping," Nano Letters, vol. 10, no. 12, pp. 5049-5055, 2010.

[10] S. Taguchi, A. Ishizumi, T. Tayagaki, and Y. Kanemitsu, "MnMn couplings in Mn-doped CdS nanocrystals studied by magnetic circular dichroism spectroscopy," Applied Physics Letters, vol. 94, no. 17, Article ID 173101, 2009.

[11] A. Ishizumi and Y. Kanemitsu, "Blinking behavior of surfacedefect and impurity luminescence in nondoped and Mn2+doped CdS nanocrystals," Journal of the Physical Society of Japan, vol. 78, no. 8, Article ID 083705, 2009.

[12] S. Taguchi, A. Ishizumi, and Y. Kanemitsu, "Multicarrier recombination and energy transfer in Mn-doped CdS nanocrystals studied by femtosecond pump-probe spectroscopy," Journal of the Physical Society of Japan, vol. 79, Article ID 063710, 2010.

[13] J. Shi, M. V. S. Chandrashekhar, J. Reiherzer et al., "Effect of growth temperature on Eu incorporation in GaN powders," Journal of Crystal Growth, vol. 310, no. 2, pp. 452-456, 2008.

[14] P. Suresh Kumar, P. Paik, A. Dhayal Raj et al., "Biodegradability study and $\mathrm{pH}$ influence on growth and orientation of $\mathrm{ZnO}$ nanorods via aqueous solution process," Applied Surface Science, vol. 258, no. 18, pp. 6765-6771, 2012.

[15] V. Srikant and D. R. Clarke, "On the optical band gap of zinc oxide," Journal of Applied Physics, vol. 83, no. 10, pp. 54475451, 1998.

[16] D. C. Look, J. W. Hemsky, and J. R. Sizelove, "Residual native shallow donor in ZnO," Physical Review Letters, vol. 82, no. 12, pp. 2552-2555, 1999.

[17] N. Han, P. Hu, A. Zuo, D. Zhang, Y. Tian, and Y. Chen, "Photoluminescence investigation on the gas sensing property of ZnO nanorods prepared by plasma-enhanced CVD method," Sensors and Actuators B: Chemical, vol. 145, no. 1, pp. 114-119, 2010.

[18] C. H. Tsai, W. C. Wang, F. L. Jenq, C. C. Liu, C. I. Hung, and M. P. Houng, "Surface modification of $\mathrm{ZnO}$ film by hydrogen peroxide solution," Journal of Applied Physics, vol. 104, no. 5, Article ID 053521, 2008.

[19] S. A. Studenikin, N. Golego, and M. Cocivera, "Fabrication of green and orange photoluminescent, undoped $\mathrm{ZnO}$ films using spray pyrolysis," Journal of Applied Physics, vol. 84, no. 4, pp. 2287-2294, 1998. 

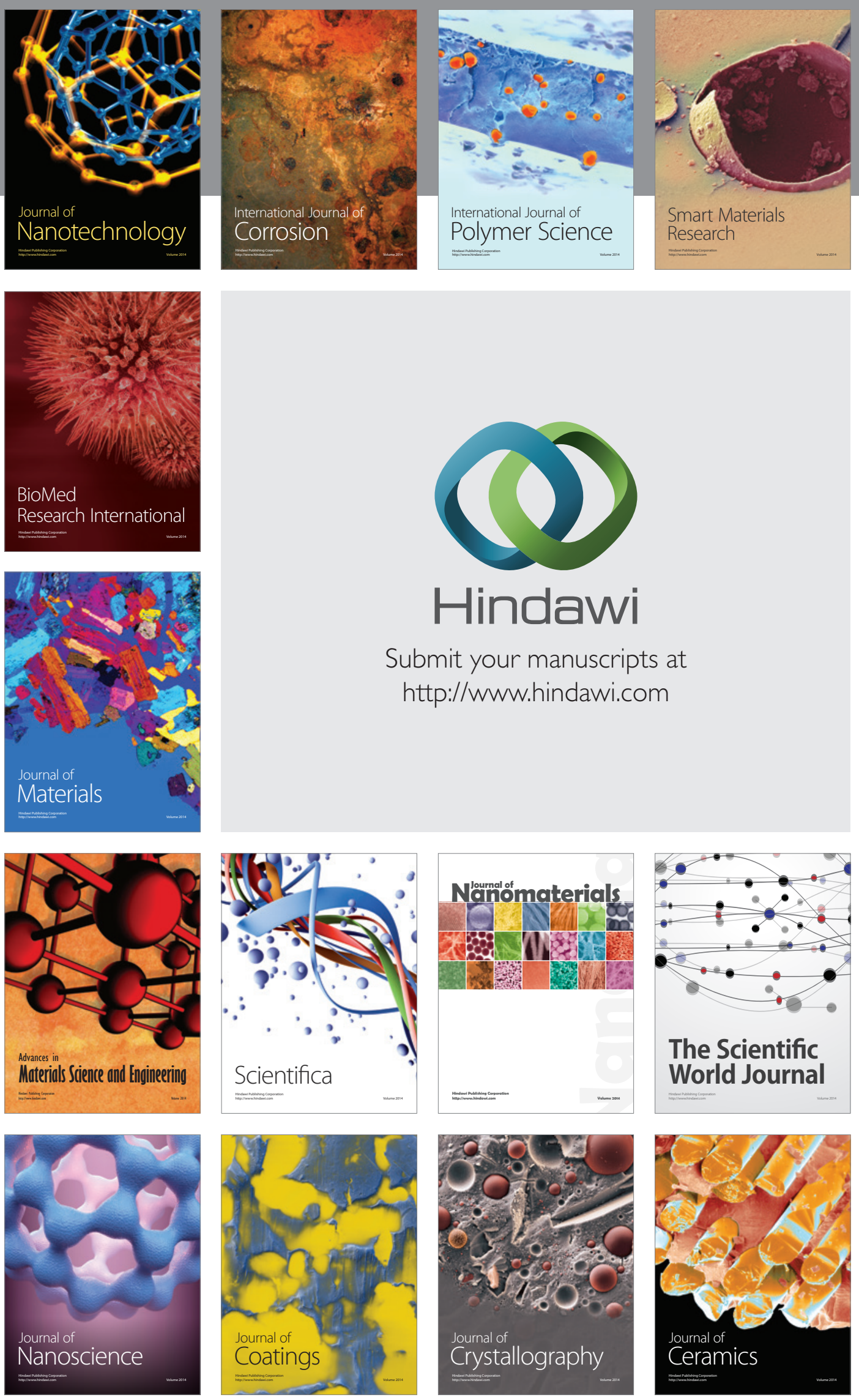

The Scientific World Journal

Submit your manuscripts at

http://www.hindawi.com

\section{World Journal}

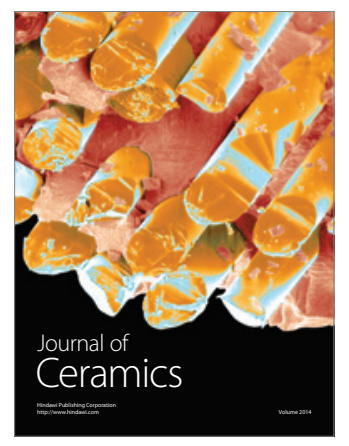

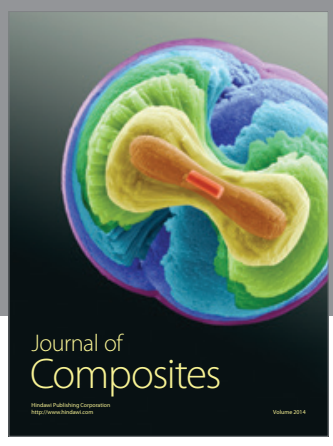
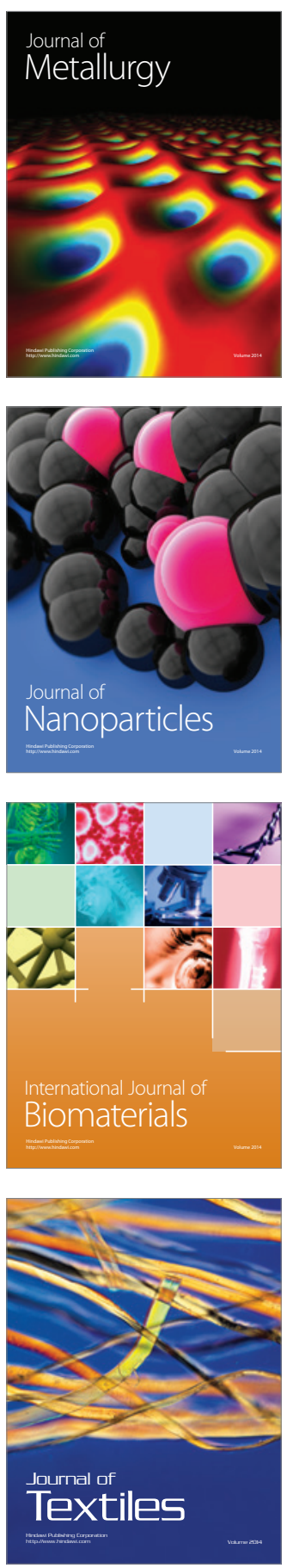